\title{
ACERCA DEL PRESUNTO EPICUREÍSMO FLORENTINO DEL SIGLO XIII
}

\author{
About the alleged Florentinian Epicureism of XIII century
}

\author{
JOSÉ BLANCO JIMÉNEZ \\ Centro de Estudios Medievales \\ Universidad Gabriela Mistral (Chile) \\ joblar@gmail.com
}

\section{Resumen}

No solo Platón y Aristóteles son recordados en la Firenze comunal. También está Epicuro, que mencionan Dante, Boccaccio y Villani. Pero ¿existió un epicureísmo florentino? En su imaginario viaje de la Commedia, Dante y Virgilio - con la ayuda divina- logran entrar en la Ciudad de Ditis, donde se encuentran los heréticos. Dentro de sepulcros llenos de fuego, deberían estar los miembros de todas las sectas y también los seguidores de Epicuro (muerto el 270 a.C.), que era conocido a través de Cicerón. En realidad, el poeta pone en evidencia a connotados gibelinos. Habla con Farinata degli Uberti e interviene también el padre de Guido Cavalcanti, al que da una ambigua respuesta que, en mi opinión, es un rayo de esperanza para uno que es tachado de sostener la “opinión de los epicúreos". Más bien podría ser un averroísta, lo que acomuna a todo un grupo de intelectuales de la época que niegan la inmortalidad del alma.

Palabras clave: Dante; commedìa; literatura medieval; epicureísmo; averroísmo.

\section{Abstract}

Not only Plato and Aristotle are remembered in the communal Firenze. Epicurus also, mentioned by Dante, Boccaccio and Villani. But was there a Florentinian Epicureism? In their imaginary trip from the Commedia, Dante and Virgil - with divine help-manage to enter Ditis City, where the heretical are. In tombs full of fire, should be members of all sects and also the followers of Epicurus (died $270 \mathrm{BC}$ ), who was known through Cicero. In fact, the poet brings out notorious Ghibellines. Talks with Farinata degli Uberti and also intervenes with Guido Cavalcanti's father, to whom gives an ambiguous answer, that is in my opinion, a ray of hope for one that is labeled as support the "Epicureans' opinion". Rather, he could be an averroist, which brings together a whole group of intellectuals of the time who deny the immortality of the soul.

Key words: Dante; commedia; medieval literature; epicureism; everroism.

Además de Platón y Aristóteles, hay otros filósofos que están presentes, durante el Medievo, en la cuna del Renacimiento. Uno de ellos es Epicuro, recordado por Dante, Boccaccio y Villani.

Pero ¿existió un epicureísmo florentino?

En su imaginario viaje de la Commedia, Dante y su guía - con la ayuda divina- logran entrar en la Ciudad de Ditis y, según explica Virgilio, en ese lugar se encuentran los heréticos. Se está entrando al Bajo Infierno, rompiendo el esquema de los pecados capitales que se había 
mantenido hasta entonces. Y es una de las tantas pruebas de los dos tiempos de composición de la obra, antes y después del exilio, como he tratado de demostrar en un trabajo que publiqué en italiano y en castellano (Blanco Jiménez, 2017, 2015, 2013).

Ed elli a me: "Qui son li eresïarche

coi lor seguaci, d'ogni setta; e molto

più che non credi son 1 tombe carche.

Simile qui con simil è sepolto,

e i monimenti son più e men caldi".

E poi ch'alla man destra si fu vòlto,

passamo tra i martiri e gli alti spaldi (If IX, 127-133)1.

No hay una señalación exacta ni de heresiarcas ni de herejías (solo se alude a Fotino a comienzos del Canto $\mathrm{XI}^{2}$ y a Arrio y Sabelio en el Canto XIII del Paradiso ${ }^{3}$ ), pero -dentro de sepulcros llenos de fuego-deberían estar los miembros de todas las sectas.

Respecto de los heresiarcas, los comentaristas y glosadores dan noticias vagas. El Ottimo Commento los llama "príncipes de herejía" (L’Ottimo Commento, ad locum). Boccaccio considera que su pena corresponde al suplicio que les correspondió en vida. Las sepulturas externamente "están muy adornadas con mármoles, labrados en oro, pinturas y de otras cosas deleitables para mirar", pero al abrirlas dentro se encuentran "llenas de huesos y de cuerpos muertos, fétidos y horribles de mirar, sin sentido, sin tener en sí potencia o virtud alguna". Los herejes parecen "personas honestas, venerables, mansas y devotas", pero dentro están "llenas de perversas y dañinas opiniones, de doctrina malvada". Los cuerpos y los huesos de los muertos, aun siendo horribles, no perjudican, pero "el hedor del veneno de las opiniones de los herejes es cosa la cual mata las almas que lo reciben dentro de sí". Además de interesantes reflexiones acerca de la

\footnotetext{
${ }^{1}$ Y él a mí: “Aquí están los heresiarcas / con sus seguidores, de todas las sectas; y mucho / más que no creas están las tumbas cargadas. / Aquí símil está sepultado con el símil, y los monumentos [sepulcros] son más o menos calientes". Y después a la mano derecha se dirigió, y pasamos entre los martirios y las altas murallas. [Para todas las citas, sigo Alighieri, Dante. La Commedia, 1996, según el texto de Antonio Lanza. La traducción me pertenece]. ${ }^{2}$ Fotino es citado por una probable relación con el Papa Anastasio II: ci raccostammo dietro, ad un coperchio / d'un grand'avello, ov'i' vidi una scritta / che dicea: Anastasio papa guardo, / lo qual trasse Foitin della via dritta [nos acercamos por detrás, a una cubierta / de una grande sepultura, donde yo vi una inscripción / que decía: papa Anastasio guardo, / al cual arrastró Fotin de la recta vía] (If XI, 6-9). Esta tradición, que tiene su origen en el Liber Pontificalis (I, pp. 258-259), fue retomada por el Decretum de Graciano (I, Dist. 19, can. 9), pasando a los cronistas medievales. Fotin habría inducido a Anastasio para obtener una indulgencia remisiva. La cuestión ha sido resuelta por Nardi (1965, pp. 7-8); después en Letture dantesche (pp. 193-207).

${ }^{3}$ Sífé Sabellio e Arrio e quelli stolti / che furon come spade alle Scritture / in render tòrti li diritti volti (Así hizo Sabelio y Arrio y aquellos estultos / que fueron como espadas a las Escrituras / en volver torcidos los derechos rostros (Pd XIII, 127-129)

110 | AlPHA No49 (DiCIEMBRE 2019) PÁGS. 109-128. ISSN 07 16-4254
} 
posición de los heréticos dentro del Infierno, describe los diferentes tipos de sepulturas (Boccaccio, 1965, ad locum).

Boccaccio tiene una seria duda acerca de la posición de los heréticos en el orden moral del Infierno: fuera de la Ciudad de Ditis se castiga solamente la incontinencia; dentro de ella debería castigarse la bestialidad y la malicia. ¿Qué lugar ocupa la herejía? ¿Es una especie singular de pecado? ¿Qué especie podemos decir que es? Y propone esta respuesta:

la herejía corresponde a bestialidad, y en ese especie se encierra, porque es cosa bestial estimar de sí mismo lo que no se debe estimar, esto es de ver y saber de alguna cosa más que no ven o saben muchos otros que de tal o de mayor ciencia están dotados, y querer, además de eso, tener firme obstinadamente su opinión contra las verdaderas razones demostradas por los otros. La cual cosa los herejes siempre hicieron y hacen, con tanta dureza de corazón teniendo y defendiendo aquello que creen verdadero, que antes se dejarían y dejan matar que ellos de aquélla se quieran remover, así como nosotros al presente vemos en éstos, los cuales sostienen que desde Celestino hasta acá no haya habido papa alguno, de los cuales más de seiscientos, en esta pertinacia perseverando, hayan sido quemados. Y por ello se pueden merecidamente reputar bestiales (Boccaccio, 1965, Inferno 9.110-133).

Pero surge una nueva duda: ¿por qué no están donde se castigan a los bestiales? La respuesta sería que no querían ofender a Dios. Es más: creían dar gusto y servir a Dios, en cuanto estimaban remover los errores con sus opiniones. Los bestiales que se castigan más abajo, blasfemaron y maldijeron, ofendiendo a Dios y a las cosas de Dios (Ivi).

Pero ¿qué es la herejía?

Francesco da Buti (1385-1395) la define así: "Herejía es elección de la propia opinión contra la determinación de la santa Iglesia; y es la herejía una de las hijas de la soberbia, acompañada siempre por la arrogancia, que es una compañera de la soberbia ..." Y agrega: "Ahora hay que saber que la herejía tiene muchas especies; pero pueden llevarse a XII, como doce son los artículos de la fe, contra los cuales se encuentran los patarinos y los heréticos han errado por diversos modos, los cuales será demasiado largo de escribir. Pero los príncipes de las sectas son estos: Epicuro, Valentino, Marzione, Fotino, Arrio, Macedonio, Prisciano, Donato, Nestorio, Euticio y muchos otros" (Da Buti, 1858, p. 133). Jacopo della Lana (1915), por su parte, incluye un listado completo (ad locum).

La herejía es toda doctrina que es sostenida con protervia contra la recta fe sostenida por la Iglesia Católica. Es diferente del error, que es una doctrina rechazada por la Iglesia, pero que no conlleva su condena siempre y cuando el que la emita preste obediencia.

En el Alto Medievo, ya habían cesado los grandes debates teológicos y las disputas iconoclastas. Es a partir del siglo XI que las herejías se originan azuzadas por una 
exigencia de reforma del clero. En conformidad con las doctrinas evangélicas, se proponen doctrinas basadas en la pobreza, como la de los patarinos milaneses de Arnaldo da Brescia y la de los Valdenses. Hacia 1140, surge el fenómeno de los Cátaros, que basaban su fe en el dualismo: toda la realidad es el resultado de un choque entre un principio bueno y espiritual y otro maligno y material. La materia es, por lo tanto, una realidad diabólica, la prisión de los espíritus celestes. Los cátaros condenaban la sexualidad como un engaño demoníaco para perpetuar la vida como existencia de la materia. El Cristo no era Hijo de Dios, sino un ángel mandado por Dios con apariencia de cuerpo humano y había nacido de María, otro ángel. Fueron importantes en Firenze a mediados del siglo XIII por su apoyo a los gibelinos. Su declinación empezó después de las batallas de Benevento y de Tagliacozzo.

Para la firmeza teológica de Dante, el tema no presenta mayor interés. Solo en el Paraíso Terrestre, Beatrice aleja a un zorro (macho o hembra da lo mismo), que sería la representación de la herejía (en recuerdo al Cantar de los Cantares 2, 15: Capite nobis vulpes parvulas, quae demoliuntur vineas) no como secta, sino como fenómeno típico del período de las grandes persecuciones. En el Canto XII del Paradiso exalta a Santo Domingo de Guzmán porque su ímpetu "percutió en las brozas heréticas" (nelli sterpi eretici percosse, $\mathrm{Pd}$ XII, 100), pero no se refiere explícitamente a la salvaje cruzada contra los Albigenses. No dice nada tampoco, en ninguna de sus obras, respecto de los otros movimientos que seguramente debe haber conocido ${ }^{4}$.

Sin embargo, Villani escribió acerca de Firenze:

Porque la ciudad estaba malamente corrupta de herejía, entre las otras de la secta de los epicúreos por vicio de lujuria y de gula, y estaba en tan grande parte que entre los ciudadanos se combatía por la fe con mano armada en varias partes de Firenze, y duró esta maldición en Firenze mucho tiempo hasta la venida de las santas religiones de san Francisco y de santo Domingo, las cuales religiones por sus santos frailes, cometido su oficio de la herética maldad por el papa, mucho la extirparon en Firenze, y en Milano, y en otras ciudades de Toscana y de Lombardía al tiempo del beato Pedro mártir, que por los patarinos fue martirizado, y después por otros inquisidores. Y por el arder de dichos fuegos en Firenze ardieron muchos libros y crónicas que más

\footnotetext{
${ }^{4}$ Respecto de Dante y las herejías - además de Manselli, Raoul, en Enciclopedia Dantesca, Roma: Istituto della Enciclopedia Italiana, 1970: II, 719b-722b- ver Tocco, Felice, Quel che non c'è nella Divina Commedia o Dante e l'eresia, Bologna: Zanichelli, 1899; L'eresia nel medio evo, Firenze: Sansoni, 1884; Proto, Enrico, Gli eresiarchi, Firenze: Leo S. Olchski, 1897, separata del Giornale dantesco V (1897), pp. 337-361. Dante se habría referido a los patarinos solo en el Fiore, una obra que se le atribuye: CXXIV 2 Sed i' truovo in cittade o in castello, / colà ove Paterin sia riparato, / credente ched e' sia o consolato / ... e'convien che per me sia gastigato [Si yo encuentro en ciudad o en castillo, / allá donde Paratin esté protegido,/ creyente que él sea o consolado]; y CXXVI 7 i' proverò ched e' son Paterini, / e farò lor sentir le gran calure [yo probaré que ellos son Patarinos, / y les haré sentir los grandes calores], allí donde se refiere al largo discurso de Falsembiante.
}

112 | AlPHA No49 (DiCIEMBRE 2019) PÁGS. 109-128. ISSN 07 16-4254 
plenamente hacían memoria de las cosas pasadas de nuestra ciudad de Firenze, de modo que pocas quedaron de ellas; por la cual cosa a nosotros ha convenido volverlas a encontrar en otras crónicas auténticas de diversas ciudades y pueblos, aquéllas de que en este tratado es hecha mención en gran parte (Villani, V, XXX).

Dante no podía estar aislado de estos enfrentamientos.

En Firenze la primera excomunión de heréticos es de 1194 por orden del obispo de Worms, legado de Enrique IV. El papa Gregorio IX interviene en 1235, designando a los frailes predicadores a cargo del tribunal de la Inquisición. Pero no resulta una tarea fácil ya que muchos de los adeptos de la herejía forman parte de los estratos altos de la sociedad y en la clase dirigente, como los miembros de las familias Baroni, Pulci, Cipriani, Cavalcanti, Saraceni y Maltresa. Un ejemplo fue, precisamente, el episodio de los hermanos Baroni, condenados en 1245 por herejes y liberados por el podestà gibelino Pace Pesamignola di Bergamo. Siguió un enfrentamiento entre las milicias de Pedro Mártir y los patarinos, que se recuerda con sendas estatuas del santo dominico colocadas sobre columnas preexistentes, ubicadas en los dos puntos principales de la sangrienta contienda: la Piazza della Croce al Trebbio y la Piazza di Santa Felicita. Como recuerda Villani, Pietro Rosini de Verona (fundador de la Compagnia del Bigallo) fue asesinado el 6 de abril 1252 por sicarios, en el bosque de Seveso, entre Milano y Como. Se le representa con una podadera incrustada en su cráneo.

En el Infierno de Dante, cada sepulcro contiene a los miembros de una secta y, según Benvenuto, estos muertos respecto de la fe viven como sepultados, porque esconden su error (Benvenuto, 1887, pp. 112-116). Y Ernesto Trucchi anota que el Círculo VI tiene algo especial: está en el mismo plano que el precedente (no desciende de la Estigia a donde están los herejes) porque la herejía pertenece igualmente a la Incontinencia y a la Malicia (Trucchi, 1996, pp. 100-105, 106-111). En efecto, Santo Tomás, comentando a San Pablo (Comm. Epist. ad. Ephesios, cap IV), dice: in talibus errantibus [aquellos que niegan la providencia divina] corrumpitur intellectus ed affectus". Ya sabemos que la corrupción del afecto o apetito es propio de los incontinentes y la corrupción del intelecto de los pésimos pecadores. Y ese primer círculo del Bajo Infierno, que contiene a los heréticos, son casi las puertas del sector más triste del reino infernal: "qui sunt portae inferi? Haeretici, quia sicut per portam intratur in domun, sic per istos intratur in infernum" (San Tommaso, Commentum in Matt. XVI). Esta observación es recordada por Nicola Fosca (Fosca, 2003, pp. 127-131).

Dante avanza dentro de la ciudad - que le recuerda las necrópolis de Arles y Polay quiere saber si se puede ver a los condenados (pensando en Farinata degli Uberti), ya que las tumbas están abiertas y sin guardias. Virgilio responde:

Ed elli a me: "tutti saran serrati quando di Iosafà qui torneranno coi corpi che là sù hanno lasciati. 
Suo cimitero da questa parte hanno

con Epicuro tutti suoi seguaci,

che l'anima col corpo morta fanno.

Però a la dimanda che mi fàci

quinc'entro satisfatto sarai tosto,

e al disio ancor che tu mi taci" (If X, 10-18) 5 .

Más que herejes, el poeta pone en evidencia a connotados gibelinos, encabezados por Farinata (con quien habla). E interviene también el padre de Guido Cavalcanti, que pregunta por su hijo, recibiendo una ambigua respuesta que, en mi opinión, es un rayo de esperanza para uno que es tachado de sostener la "opinión de los epicúreos" en el Decameron. Pero sus escritos - como diré- pueden llevar a considerarlo más bien como un averroísta (acusación que también pesó sobre Dante), adscrito a los anticlericales "Fieles de Amor".

Lo que, en realidad, coliga a todo este grupo de intelectuales es que niegan la inmortalidad del alma y -en ese sentido- "epicúreo" resulta solo una cómoda etiqueta para clasificar a importantes personajes proclives al laicismo, que son puestos bajo la égida de un filósofo conocido solo por sus vistosos rasgos materialistas. Además, como anota Francesco Mazzoni, Dante traduce un paso del comentario de Servio a la Eneida: secundum Epicureos, qui animam cum corpore dicunt perire (Mazzoni, 1976, p. 137).

¿En qué consistía el Epicureísmo del siglo XIII?

He revisado todos los comentarios a la Commedìa disponibles del siglo XIV y los resultados más interesantes son los siguientes.

Jacopo della Lana (1324-28) recuerda que los epicúreos opinaban que el alma moría con el cuerpo y que todas las cosas que tienen principio similar y proceso similar, deben tener similar fin (Lana, Inferno 10.13-15) y el Ottimo Commento (1333) se refiere a la secta de los Epicuros según lo que afirma Cicerón en el segundo libro de $L a$ naturaleza de los dioses, citando argumentos tomistas y aristotélicos para demostrar que "la opinión de los Epicúreos es falsa, y llena de error" (pp. 10-15). Por su parte, Giovanni Boccaccio (1373-75) señala que "Epicuro fue solemnísimo filósofo y muy moral y venerable hombre en los tiempos de Filippo, rey de Macedonia y padre de Alejandro. Es verdad que él tuvo algunas perversas y detestables opiniones, porque él negó del todo la eternidad del alma y sostuvo que todas juntas con el cuerpo muriese, como hacen aquellas de los animales brutos; y así todavía otros filósofos más varia y perversamente estimaton del alma. Sostuvo también que hubiese suma beatitud en los deleites carnales, las cuales

\footnotetext{
${ }^{5}$ Y él a mí: «todos serán cerrados / cuando de Josafat aquí volverán / con los cuerpos que allá arriba han dejado. / Su cementerio por esta parte tienen / con Epicuro todos sus seguidores, / que el alma con el cuerpo muerta hacen. / Pero a la pregunta que me haces / aquí dentro de poco serás satisfecho, / y al deseo también que tú me callas».

114 | AlPHA No49 (DiCIEMBRe 2019) PÁGS. 109-128. ISSN 07 16-4254
} 
satisfaciesen el apetito sensible, así como a los ojos era sumo bien poder ver aquello que ellos deseaban y que les gustaba ver, así a los oídos oír y a las manos tocar y al gusto de comer. Y estiman muchos que este filósofo fuese un hombre golosísimo; la cual estimación no es verdadera, porque ningún otro fue más sobrio que él; pero para que él sintiese ese deleite, en el cual ponía que estaba el sumo bien, sostenía largamente el hambre, o queríamos más bien decir el deseo de comer, el cual, muy portado, no utilizaba el pan, sino que las raíces de las hierbas selváticas maravillosamente gustaban y con deseo se comían; y así, sostenida largamente la sed, no los vinos débiles, sino el agua, e incluso la no pura, gustaba y apetitosamente se bebís; y similarmente de cada otra cosa ocurría. Y por ello no fue goloso, como muchos creen; ni fue por ello su sobriedad loable, en cuanto a un loable fin no la usaba. Por lo tanto, por estas opiniones, separadas del todo de la verdad, así como herético lo muestra el autor en este lugar estar condenado, y con el todos aquellos los cuales siguieron sus opiniones" (Boccaccio, 1965, pp. 13-15) ${ }^{6}$.

El comentario de Cristoforo Landino (1481, pp. 13-15) es extremadamente iluminante acerca del conocimiento que se tenía de Epicuro en el ambiente florentino, pero fue escrito en torno a 1481 y -a ese punto- ya se conocía el De rerum natura, descubierto por Poggio Bracciolini en 1417, en algún lugar del Sur de Alemania. ${ }^{7}$

Pero, ¿qué sabía Dante de Epicuro?

He aquí lo que escribe en el Convivio IV VI 11-12:

Hubo otros filósofos y de éstos fue primero y príncipe un filósofo, que fue llamado Epicuro, que viendo que cada animal, tan pronto que ha nacido, es casi por naturaleza dirigido en el debido fin, que rehúye el dolor y demanda alegría, dijo que aquel fin nuestro es la voluptad (no digo 'voluntad', sino que escribo con $P$ ), es decir deleite sin dolor. Y puesto que, entre el deleite y el dolor no ponía término medio alguno, decía que 'voluptad' no era otra cosa que 'no dolor', así como parece Tulio recitar en el primero de Fin de los Bienes. Y de este, que de Epicuro son nominados Epicúreos, fue Torcuato noble romano, descendido de la sangre del glorioso Torcuato del cual hice mención más arriba. (IV vI 11-12) [Traduzco voluptade con voluptad en vez de "voluptuosidad" o "deleite", porque me parece un arcaísmo válido] (ed. Brambilla Ageno).

\footnotetext{
${ }^{6}$ ¿De cuál fuente obtuvo Boccaccio la información acerca de la frugalidad de Epicuro? No pudo conocer a Diógenes Laercio, porque fue traducida al latín por Ambrogio Traversari recién a fines del siglo XV. Tendrá que haber leído una versión latina de la carta a Meneceo (Los alimentos más sencillos producen tanto placer como la mesa más suntuosa, cuando está ausente el sufrimiento que causa la necesidad; y el pan y el agua proporcionan el más vivo placer cuando se toman después de una larga privación. El habituarse a una vida sencilla y modesta es pues un buen modo de cuidar la salud y además hace al hombre animoso para realizar las tareas que debe desempeñar necesariamente en la vida) o tal vez recordó las apreciaciones que Cicerón hace en las Quistioni Tusculane acerca de la vida frugal (ver Tusculanae Disputationes, V 97).

${ }^{7}$ Acerca de este episodio de la historia de la filología, ver El giro. De cómo un manuscrito olvidado contribuyó a crear el mundo moderno. Barcelona: Crítica, 2012 (Ed. original: The Swerve. New York: Norton, 2011).
} 
El texto de Cicerón está plenamente identificado y es citado prácticamente por todos los comentaristas: quod summum bonum esse vult, summumque malum dolorem (De Finibus bonorum et malorum I IX 29-30: el sumo bien está en el deleite y sumo mal en el dolor).

Otro texto que recuerdan los comentaristas de Dante es aquel en que Epicuro juzga que en la privación de todo dolor está la suma felicidad: Maximam voluptatem illam habemus quae percipitur omni dolore detracto" (Ibidem, I II 37: sino que tenemos como máximo aquél que se percibe suprimido todo dolor).

En cuanto a Lucio Torquato, también es citado por Cicerón: Accurate autem quondam a L. Torquato, homine omni doctrina erudito, defensa est Epicuri sententia de voluptate (Ibidem IV 13: Recuerdo que, en cierta ocasión, Lucio Torquato, varón erudito en toda ciencia, defendió con mucha habilidad la opinión de Epicuro sobre el deleite). Esto porque distinguía entre voluptas y cupiditas: la voluptas epicúrea no es codicia carnal, sino deleite sin dolor.

La actitud de Dante para con Epicuro es positiva. Incluso, propone una alegoría en la que contamina historia profana y escritura sacra: las tres Marías van a ver el cadáver del Cristo y encuentran a un joven vestido de blanco que les dice que no está ahí:

Por estas tres mujeres se pueden entender las tres sectas de la vida activa, esto es los Epicúreos, los estoicos y los Peripatéticos, que van al monumento, esto es al mundo presente que es receptáculo de cosas corruptibles, y preguntan por el salvador, esto es la beatitud, y no la encuentran; pero encuentran un joven en vestiduras blancas, el cual según el testimonio de Mateo... era ángel de Dios... Este ángel es esta nobleza nuestra que viene de Dios... que habla en nuestra razón, y dice a cada una de estas sectas, esto es a cualquiera que va buscando beatitud en la vida activa, que no está aquí (Convivio IV XXII 15-16).

Y lo había adelantado:

Por las cuales virtudes si sube a filosofara aquellas Atenas celestiales, donde los Estoicos y Peripatéticos y epicúreos, por la l[uz] de la verdad eterna, en una voluntad concordemente concurren" (Convivio III XIV 15).

Resulta desconcertante esta evaluación de Dante en el Convivio si después en el Inferno condena a Epicuro. Incluso, algunos han pensado que conocía solo el Libro I del De Finibus y que después se habría enterado del dogma de la mortalidad del alma (Padoan, 1959, pp. 12-39) o que pensó en dos tradiciones diferentes: la ciceroniana y la cristiano-medieval (Mazzeo 1958, pp.106-120).

De hecho, en el Convivio, condena esa doctrina sin mencionar a Epicuro:

Digo que entre todas las bestialidades aquélla es estultísima, vilísima y muy dañina, quien cree que después de esta vida no hay otra vida; porque, si nosotros revisamos 
todas las escrituras, tanto de los filósofos como de los otros sabios escritores, todos concuerdan en esto, que en nosotros hay alguna parte perpetua. Y esto máximamente parece querer Aristóteles en aquél del Alma; esto parece querer máximamente cada uno de los estoicos; esto parece querer Tulio, especialmente en ese librito de la Vejez; esto parece querer cada uno de los poetas que según la fe de los gentiles han hablado; esto quiere cada una de las leyes, Judíos, Sarracenos, Tártaros y cualesquiera otros viven según alguna razón. Que si todos fuesen engañados, seguiría una imposibilidad que tan solo describir sería horrible (Convivio II VIII 8-9).

La posición de Dante respecto del epicureísmo en el Convivio se apega a Cicerón y se aleja de la vulgata. En el plano de la vida activa, la voluptas epicúrea adquiere un valor positivo, históricamente confirmado en el desarrollo de las doctrinas morales que desde los estoicos conduce a la opinión de los peripatéticos. En Aristóteles está la autoridad filosófica que, junto con la imperial, permitirá un perfecto gobierno de los hombres y que indique el verdadero fin de la vida humana.

Del Lungo, en su comentario, acepta que Epicuro no puede ser considerado un heresiarca en el sentido eclesiástico, pero los negadores de la espiritualidad del alma y de su supervivencia a la muerte corporal eran en el Medievo (especialmente los heréticos Paterinos) denominados Epicúreos, porque seguían esa doctrina (Del Lungo, 1926, pp. 1316; Pagnoni-Spurlese, 1974, pp. 1443-1477). Si los epicúreos son negadores oficiales y tradicionales de la inmortalidad del alma, quienquiera niegue tal inmortalidad es epicúreo (Corti, 2003, p. 331).

A ello hay que agregar que la idea de la haeresis, como secta aplicable a los epicúreos, tiene una tradición muy antigua. ${ }^{8}$ Los que se encuentran en esa tumba son herejes que, además, sostuvieron un dogma contrario a la fe cristiana. Como señalé, en el Convivio, los epicúreos aspiran a la Atenas celestial (con los estoicos y los aristotélicos), pero en la Commedìa esta se ha visto reducida al Limbo donde eternamente sentirán el deseo de ver a Dios. Demócrito está allí, pero no Epicuro (Blanco Jiménez, 2007, pp. 2730). Es que porque los epicúreos están manchados con una específica postura contra la fe que salva.

¿Quiénes están en la tumba a la que se acerca Dante?

En primer lugar, Manente degli Uberti (más conocido como Farinata) con el que tiene un encendido intercambio de palabras sobre un tema político, que no tocaré aquí. ${ }^{9}$ Este importante jefe gibelino fue condenado post mortem por el inquisidor Salomone da

\footnotetext{
${ }^{8}$ Philosophi quoque Stoici, Peripatetici, Academici, Epicurei, illius vel illius haereseos appellantur (Eusebius Sofronius Hieronymus, Enarrationes in epístolas Beati Pauli xxxv.3, en Migne, Jacques-Paul (1878) Patrologiae Cursus Completus, Garnier, Paris: CXII, col. 690).

${ }^{9}$ Recuérdese la profecía del exilio (If X, 77-81), cuya irrevocabilidad domina la escena al punto de que la mención de los otros “magnánimos” resulta apresurada, Ver Pasquini (2012, p. 8).
} 
Lucca, en 1283, según parece por haber pedido, en punto de muerte, el sacramento de los cátaros: el "Consolamentum" ". Sus restos fueron exhumados dos décadas después de su muerte (probablemente Dante, a sus 18 años fue testigo del acontecimiento) y confiscados los bienes de sus herederos ${ }^{11}$. Según parece, otros gibelinos corrieron la misma suerte, porque su exaltada incredulidad los llevó a identificarse con los herejes. De allí que se registren históricamente estos gritos: ghibellini, paterini! y moiano i patarini ghibellini! Ahí se encuentra también Cavalcante de' Cavalcanti (que interrumpe la conversación) sobre el que escribe Cristoforo Landino (1481) que pertenecía a una familia "muy antigua en nuestra ciudad; y ennoblecida por no pocos excelentes hombres producidos por aquella fácilmente se puede ver en las crónicas florentinas". Entre ello está el hijo Guido "precipue agudísimo dialéctico, y filósofo egregio, y no poco ejercitado en los versos toscanos, los cuales todavía hoy viven llenos de gravedad y de doctrina" (Landino, 1481, pp. 52-54). Hasta hace pocos años, se pensó que Farinata y Cavalcante habrían sido consuegros por un matrimonio de conveniencia civil entre Beatrice, hija del jefe gibelino y Guido. Sin embargo, Francesco Velardi (2007) ha demostrado que el consorte era un homónimo, que falleció en 1310 (pp. 239-263).

En las figuras de Farinata y Cavalcante, la voluptas terrena se aprecia bajo la luz de la justicia divina, porque la beatitud de la vida activa se encuentra solo en la contemplación celeste. El epicureísmo de ambos se expresa en el haber vivido el hinc et nunc, que ahora no los abandona: están obligados a conocer solo el presente y así lo entendió Antonio Gramsci (1996, pp. 72-91). En su tiempo contingente, Farinata tiene preocupaciones políticas; Cavalcante cree que Dante viaje por el Infierno por "altitud de ingenio". Y el poeta le aclara que se mueve por la ultratumba porque está siendo guiado a una meta superior. Dirá a Cavalcante que el que allá lo espera lo conduce forse, Cui Guido vostro ebbe a disdegno If X, 63 y provocará la desesperación del padre.

Cesare Bozzetti señala que Dante inserta un elemento estrictamente autobiográfico para evidenciar que las luchas ideológicas y políticas han generado discordias en el mundo y entre los condenados en el más allá. Allí se introduce el motivo de la gracia que se concede a Dante, que es la única que le permitirá llegar a Beatrice. La aparición de Cavalcante enfatiza "el motivo de la altura de ingenio alejada de la verdad, la causa intelectual de la culpa de la que Farinata es la consecuencia en el plano de la acción" (Bozzetti, 1957, p. 97). Además, cree que no es exacto "hablar de 'epicúreos' por los protagonistas de este canto,

\footnotetext{
${ }^{10}$ Para la acusación de herejía a Farinata, ver Barbi (1941, p. 157). El texto de la condena póstuma se puede leer en Ottokar (1948, pp. 115-123)

${ }^{11}$ Arsenio Frugoni (1966, pp. 261-283) se refiere a la naturaleza de la acusación de herejía cátara pronunciada contra Farinata y su mujer, como asimismo analiza las relaciones entre cátaros y gibelinos. Concluye que Dante no pone en esa tumba a patarinos o gibelinos, y ni siquiera averroístas, sino solo “epicúreos", entendiendo como tales a los que hacen muerta el alma con el cuerpo.
} 
que solo son, según las precisas palabras dantescas, seguidores de Epicuro en el sentido susodicho. Ni por eso, se puede evocar como trasfondo de su representación una tradición de vida y de pensamiento epicúreos" (Bozzetti, 1957, p. 109).

El episodio ha sido analizado sobre todo por el disdegno de Guido, cuestión que Antonino Pagliaro resumió en un artículo que es un clásico. Cavalcante cree que Dante está de paso por el Infierno "por altura de ingenio" y se extraña de que Guido no esté con él. La respuesta del poeta (Da me stesso non vegno: / colui ch'attende là per qui mi mena /forse, Cui Guido vostro ebbe a disdegno, If X, 61-63) -que lo hace desfallecer-tiene su meollo sintáctico en el "cui", que ha sido considerado como complemento directo de la locución ebbe a disdegno, el sujeto del que se indicaba en Guido.

Hace más de 40 años, en un pullman, de vuelta de una excursión que formaba parte de un Congreso Internacional, planteé el tema al Prof. Aldo Vallone y este me sugirió que leyera la interpretación de Auerbach. Lo hice y creo que -sinceramente- va por el camino equivocado (a no ser que la traducción del original no sea muy buena). El filólogo judío alemán sostiene que la "Divina Comedia" sería la consumación de tendencias presentes a partir de la descomposición de la tradición literaria clásica y el desarrollo de la cristiandad medieval: "han sido los poetas de la antigüedad los que le han servido a Dante, antes que a nadie, de modelo para su estilo elevado... y en el De vulgari eloquentia nos confiesa cuánto les debe por el estilo elevado del lenguaje vulgar. Hasta lo dice en ... el tan discutido verso donde expresa que quizá Guido Cavalcanti haya desdeñado a Virgilio" (Auerbach, 1950, p. 175).

D'Ancona (siguiendo a Torraca) creyó en un desdén para con Beatriz "en la cual Cavalcanti no vio ese rayo de luz divina, que Dante supo reconocer" (D'Ancona, 1912, pp. 218-219). Con bastante éxito el ya citado Pagliaro reconstruyó el significado de la manera siguiente: "este me conduce a través de estos lugares donde quien vuestro Guido desdeñó, se rehusó a venir", con la consecuente precisión semántica del ebbe (Pagliaro, 1953, p. 378). El "quien" sería Beatrice, pero no como persona histórica, sino como símbolo de la sabiduría teológica. Y, además, sería una "meta directa", porque la "meta final" es Dios.

Varios estudiosos se han inclinado por esta posibilidad, poniéndola en relación con la muerte de Beatrice y con el soneto I' vegno 'l giorno a te 'nfinite volte de Guido Cavalcanti $^{12}$.

\footnotetext{
${ }^{12}$ Acerca de toda esta temática -que no puedo tratar aquí- hay una amplísima bibliografía. Solo cito: Del Lungo, Isidoro. "Il disdegno di Guido". Nuova Antologia (10 novembre1889), pp. 37-67 (después en (1898) Dal secolo e dal poema di Dante. Bologna: Zanichelli, 1898, pp. 1-61); D’Ovidio, Francesco. "Il disdegno di Guido", Studii sulla Divina Commedia. Palermo: Sandron, 1901, pp. 150-201; Parodi, Ernesto Giacomo. "La miscredenza di Guido Cavalcanti e una fonte del Boccaccio". Bullettino della società dantesca, XXII (1915), pp. 37-47; Mazzoni, Guido. "Il disdegno di Guido (Inf. X, 32-63)", en Almae luces malae cruces: studii danteschi. Bologna: Zanichelli, 1941, pp. 213-221; Chimenz, Siro Amedeo. "Il disdegno di Guido e i suoi interpreti”, en Orientamenti culturali I(1945), pp. 179-188.
} 
Según parece, sí hubo un disidio entre ambos poetas, pero -como plantea Mario Marti (1970)- este podría tener una explicación política, puesto que los Ordenamientos de Justicia de Giano della Bella (1293) excluyeron a los nobles y magnates (como Guido) del gobierno de la cosa pública y, con los segundos Ordenamientos (6 de julio de 1295), se estableció que podían inscribirse en las Artes, para participar en la vida política, los nobles no magnates que no ejercitaran ninguna de ellas (como Dante). O sea, Guido quedó excluido de las corporaciones artesanas y su única fuerza fue la propia potencia familiar, incluida su facciosa y adusta violencia.

Dante asumió un compromiso ciudadano, que lo llevó a madurar y a cambiar las exigencias literarias de la Vita Nova. Guido habría permanecido anclado a su ideal de quisquillosa aristocracia de la cultura, considerado aún como maestro del Stilnovo florentino. Y el disidio podría haber empezado en el De vulgari eloquentia, cuando Dante atribuye la preeminencia en el ámbito stilnovístico a Cino da Pistoia (I XIII 3) y Guido solo forma parte del grupo de los elegidos. En la Commedia, en cambio, Cino no es recordado, pero sí Guido, aunque yo lo excluyo de la profecía de Oderisi da Gubbio (Blanco Jiménez, 2000, pp. 77-83).

En todo caso, no había razón para que Guido desdeñase a Virgilio por su poesía latina o porque era símbolo del Imperio o porque era símbolo de la razón iluminada por la fe. Tanto menos que desdeñase a Beatrice (histórica o simbólica) o - más absurdo aun - que, como algunos piensan, Dante hubiera querido "vengarse" de Guido en el Infierno. Si bien el "otro Guido" de Pg XI, pp. 97-99, no es Cavalcanti, lo salva con el Cui Guido vostro ebbe a disdegno, como diré a continuación.

Ha venido a poner un poco de orden Letterio Cassata (1969) con un trabajo que me parece resolutivo (Cassata, 1969, pp. 5-49), porque -analizando a todos los comentaristas, y palabra por palabra el texto dantesco- ha dejado en claro que (citando a Dario Rastelli, 1948) en nombre de Guido "se resume, tal vez, los temas fundamentales [de todo el canto]: la cortesía, la inteligencia, el epicureísmo, el exilio, el pathos de los afectos familiares" (p. 21). El episodio pone en la conciencia de Dante la coexistencia en Guido de la altura de ingenio y de la incredulidad. Según Cassata, su disdegno consiste en su alejamiento de la verdadera fe por su excesiva confianza en las fuerzas humanas y el cui está usado elípticamente y no es un simple complemento directo, esto es quem o quod (p. 41). O sea, como propuso Pio Rajna, significa "Aquel (Dios) a quien Guido tuvo en desdén (desdeñó)" y así lo cita Francesco D’Ovidio (1878, pp. 328-329). Así se comprende mejor la postura del forse, porque si se hubiera referido a Virgilio, Dante habría podido escribir: cui forse Guido vostro ebbe a disdegno. El desdén para con la divinidad debe ser considerado carácter constitutivo de toda herejía y, al respecto, Cassata 
cita a San Agustín y a Santo Tomás. ${ }^{13}$ Dante habría podido, por un mal entendido sentimiento cristiano y de amistad, ocultar la amarga verdad, però fu la risposta così piena [por eso fue la respuesta tan plena, If X, 66].

Aclarado hasta aquí el punto del disdegno, me parece importante referirme a los otros "habitantes" de la tumba.

Federico II de Suevia vivió entre 1194 y 1250, fue coronado Emperador en San Pedro, Roma, el 20 de noviembre de 1220 y se estableció en el Reino de Sicilia. Contra él se tejió varias leyendas, incluso recientes (Alessandri; Li Vigni), pero resulta innegable que tuvo una tensa relación con el Papado (llegaron a calificarlo como un preámbulo del Anticristo). En su corte sostuvo y financió una brillante actividad cultural: la poesía (provenzales que huían de la guerra contra los albigenses, la Magna Curia del Reino de Sicilia), la música (Walther von der Vogelweide), el estudio del comportamiento de los animales (por ejemplo, su Liber de arte venandi cum avibus), la apertura hacia el pensamiento aristotélico y árabe. No entro en consideraciones filológicas, porque no viene al caso ${ }^{14}$, pero lo que sí me interesa es poner en evidencia que las obras de Averroes se conocieron por intermedio de la corte federiciana. ${ }^{15}$

Todos concuerdan en que ' $l$ Cardinale (If X 120) es Ottaviano degli Ubaldini, descendiente de una noble familia gibelina del Mugello. Su actividad política como legado apostólico ha sido juzgada como ambigua, tanto en Romagna como en Italia meridional. Murió en octubre de 1273 y -cuando Dante escribe- la ideología política de los seguidores de Federico II se confunde con presuntos motivos ético-religiosos.

$\mathrm{O}$ sea, en el cimitero de los epicúreos, no se encuentran solo aquellos que disfrutaron de la vida material (Farinata y Cavalcante no están en esa categoría), o

\footnotetext{
${ }^{13}$ Si qui sententiam suam, quamvis falsam atque perversam, nulla pertinaci animositate defendunt, quaerunt autem cauta sollicitudine veritatem, corrigi parati cum invenerint, nequaquam sunt inter haereticos deputandi (Augustinus, Epist. XLIII ad Glorium, Eliseum etc., cap. I: PL 33, 160: Si uno defiende sin animosidad y sin obstinación la propia opinión, aunque sea falsa y perversa, y busca con la debida solicitud la verdad, listo para seguirla cuando la encuentra, no se puede incluir entre los heréticos); y agrega Santo Tomás: quia scilicet non habent electionem contradicentem Ecclesia doctrinae ([39291] Summa theologiae, II ${ }^{\mathrm{a}}$ II ae q.11 a. 2 ad 3: porque no tiene la determinación de contradecir la enseñanza de la Iglesia).

${ }^{14}$ Los interesados pueden consultar Riedmann, Josef. "Unbekannte Schreiben Kaiser Friedrichs II. und Konrads IV. in einer Handschrift der Universtitätsbibliothek Innsbruck. Forschungsbericht und vorläufige Analyse". Deutsches Archiv für Erforschung des Mittelalter LXII (2006), pp.135-200; Schaller, Hans Martin. "Zur Entstehung der sogenannten Briefsammlung des Petrus de Vinea". Deutsches Archiv für Erforschung des Mittelalters XII (1956), pp. 114-159; (1957-1958) "Die KanzleiKaiser Friedrichs II. Ihr personal und ihr Sprachstil”. Archiv für Diplomatik III (1957), pp. 207-86, IV (1958), pp. 264-327; y (1986) "L'epistolario di Pier della Vigna”, en Politica e cultura nell'Italia di Federico II. Ed. Gensini, Sergio. Pisa, Pacini 1986, pp. 95111; Niese, Hans. "Zur Geschichte des geistigen Lebens am Hofe Kaiser Friedrichs II". Historische Zeitschrift 108 (1912), p. 517; Delle Donne, Fulvio "Lo stile della cancelleria di Federico II ed i presunti influssi arabi", Atti dell'Accademia Pontaniana, n.s. 41 (1992), pp. 153-164.

${ }^{15}$ Existe una carta cuyo texto está en Guerin De Vaux, Roland, "La première entrée d'Averroès chez les latins", en Revue de Sciences Philosophiques et Théologiques, XXII (1933), p. 206.
} 
gibelinos (Cavalcante no lo era). Por su parte, Ottaviano degli Ubaldini es gibelino, pero cardenal de la Iglesia Católica Apostólica Romana. Finalmente, la búsqueda del quieto vivir no se condice con ninguno de ellos: todos tuvieron vidas agitadas, dedicados a la acción pública y a modificar el statu quo de la Cristiandad y la Toscana.

Lo único que podría acomunarlos es que hayan sido "fautores" de los cátaros. Como ninguno tiene descendientes que pudieren ser perseguidos, Dante evitaría ese riesgo. Pero eso no aclara el porqué se les considera epicúreos. La explicación estaría en la posición filosófica de Guido Cavalcanti.

¿Y qué era Guido Cavalcanti, en realidad?

Giovanni Boccaccio (1373-75) lo identifica como hombre muy comedido y rico y de alto ingenio, y supo muchas agraciadas cosas hacer mejor que algún otro nuestro ciudadano (Boccaccio, 1965, 64-66) y lo pone como protagonista de una novella, calificándolo como "un de' miglior loici che avesse il mondo e ottimo filosofo naturale" (Boccaccio, 2013, pp.1018-1022).

Guido Cavalcanti es recordado también por Giovanni Villani, Dino Compagni, Domenico Bandino d'Arezzo, Gianni Bartoli da Serravalle, Filippo Villani y Franco Sacchetti (Trecentonovelle, Novella LXVIII) como "hombre de porte noble, intelectual solitario, cultísimo, lógico sutil, «filósofo natural» de actitud siempre aristocráticas, ya irónicas ya desdeñosas o levemente maqueteadas de esnobismo, elegante a caballo, buen jugador de ajedrez" (Corti, 2003, pp.10-11).

Son datos indesmentibles que Guido Cavalcanti nació alrededor de 1255 y que fue el líder reconocido de ese conjunto de poetas refinados que habría de llamarse dolce stil novo por indicación del mismo Dante (Pg XXIV, 57). Los fundamentos filosóficos de dicho movimiento se encuentran en la canción Donna me prega, dando inicio a la teoría del amante fedele d'Amore. Su amistad con Dante está certificada por la respuesta que dio al soneto A ciascun'alma presa e gentil core, en torno a 1283, que el enamorado de Beatrice envió a otros poetas, según relata él mismo en Vita Nova III 14-15. Allí menciona al que llama "primo de li miei amici", que respondió con otro soneto: Vedeste, al mio parere, onne valore. Ese fue el comienzo de la amistad, que ha sido ampliamente estudiada y que yo, en este trabajo, limito a dos acontecimientos fundamentales: el influjo fundamental que recibió Dante acerca de la concepción del amor, que toma su estado donde está la memoria (esto es en el alma sensitiva); y la dolorosa decisión de tener que aceptar, como uno de los Priores, la expulsión de Guido al exilio, después del tumulto de San Giovanni (1300) ${ }^{16}$.

\footnotetext{
${ }^{16}$ Acerca de la relación de amistad poética y filosófica, cfr. Nardi, Bruno. "Dante e Guido Cavalcanti". Giornale storico della letteratura italiana CXXXIX (1962), pp.481-512; ahora en Saggi e note di critica dantesca, Milano-Napoli: Riccardo Ricciardi, 1966, pp. 190-219; Pasero, Nicolò. "Dante in Cavalcanti: ancora sui rapporti tra Vita nova e Donna me prega”, en Medioevo romanzo, XXII (1998), pp. 388-414.
}

122 | AlPHA No49 (DiCIEMBRe 2019) PÁGS. 109-128. ISSN 07 16-4254 
Un aristocrático sin problemas económicos como, en cambio, los tuvo Dante. Un intelectual diverso del tipo que describe Jacques Le Goff, ya que no era un docente universitario, aparecido con el resurgimiento de las ciudades, asalariado o miembro de una orden religiosa (Le Goff, cap. III). Era, por sobre todo, un librepensador, y-lo que es más importante- era libre de serlo. Del mismo modo como fue un político, que tenía la libertad para defender los intereses de su clase social. Y -como ya dije-el tema teológico se había transformado en tema político: patarinos, cátaros, valdenses estaban contra la mundanidad del clero y la injerencia de la Iglesia en los asuntos temporales. Además, los gibelinos eran acusados de conducir una vida fastuosa según el presunto ejemplo de Federico II y Manfredi.

Solo que Guido no era gibelino. Por otro lado, el ideario de los "fieles de amor" no tiene nada de herético.Y, entonces, ¿por qué se podría asegurar que fuese epicúreo?

Bruno Nardi ha visto -con justa razón, me parece- que Cavalcanti no seguiría convicciones epicureístas, sino averroístas. Y logra demostrarlo analizando precisamente la canción Donna mi prega ${ }^{17}$. El poeta habría aceptado las proposiciones de la individualidad del alma sensitiva, como única forma y perfección del cuerpo, y de su muerte con el cuerpo mismo. Así lo interpreta el médico y maestro florentino Dino del Garbo que, en una glosa, subraya los aspectos irracionales y patológicos de ese amorpasión: "el amor del que trata Cavalcanti en esta canción es una pasión del alma sensitiva, como la ira, el temor, la tristeza y otros movimientos sensibles que no se encuentran en el intelecto, cum potentia concupiscibilis, que sedes amoris est, sit potentia sensitiva, como pensaba también Dante al tiempo de la Tenzone con Cino, cuando enviaba a este el soneto Io sono stato con Amore insieme, acompañándolo con la epístola Eructuavit incendium" (Nardi, 1985, p. 82).

Para Averroes y el Averroísmo en Dante, sugiero la consulta de las voces respectivas en la Enciclopedia Dantesca, magistralmente redactadas por Cesare Vasoli (1970). Dante lo coloca en el Limbo (If IV, 144) y lo recuerda en Cv IV XIII 8. Además, lo cita en la Monarchia, cuando establece la diferencia entre el fin "natural" y el fin "sobrenatural" (Mn III XV7): la visión beatífica de Dios que el hombre no puede alcanzar nisi lumine divino adiuta; y el que se alcanza en la felicidad mundana y consiste en la operación de la virtud intelectiva propia del hombre. En otro paso (Mn I III 8), declara expresamente que para la plena actuación del intelecto humano no es suficiente la obra de cada individuo, sino de la entera Humanidad de la que forma parte. Esto, precisamente, según Averroes ${ }^{18}$.

\footnotetext{
${ }^{17}$ Respecto de este tema, Blanco Jiménez, José (2013).

${ }^{18}$ No se trataría de averroísmo, sino simplemente de que el individuo solo no basta para que se actúe la potencia del intelecto y requiere de la humana civilitas (ver Gilson, Étienne. Dante et la philosophie. Paris: Librairie Philosphique J. Vrin, 1953, p. 170). Por otro lado, en Mn I III 9, alude a su doctrina de la unidad del intelecto posible y, en Pg XXV, 63, rechaza la tesis del intelecto separado. Sobre este argumento, puede verse también
} AlPHA No 49 (DicIEMBRE 2019) PÁGS. 109-128. ISSN 07 16-4254| 123 
Insiste Nardi: la doctrina característica de Averroes es "la de la unidad del intelecto posible, el cual es una substancia separada, que no puede decirse en sentido propio forma y perfección del cuerpo humano" (Nardi, 1985, p. 84). Y agrega más adelante: esta substancia separada es "inmortal, única para toda la especie humana, la cual se une a los individuos singulares por medio de las imágenes sensibles o fantasmas, de los cuales el intelecto agente extrae la idea pura inteligible" (Nardi, 1985, p. 86). Y, en lo que se refiere a la canción Donna mi prega, Nardi tiene claro que el concepto de la pasión amorosa, para Cavalcanti, reside "en el alma sensitiva que es forma del cuerpo humano, mientras el intelecto posible, que no es forma del cuerpo, es inmune a ella" (Nardi, 1985, p. 86).

Hasta allí el raciocinio de Nardi es aceptable, pero es muy distinto pretender que el averroísta Guido haya tratado de salvar a Dante de su traviamento ("descarrío") filosófico o teológico. Asimismo, me parece discutible que no haya querido seguirlo, buscando una moral que lo aislaba de la sociedad cristiana.

Definitivamente, no estoy de acuerdo. Dante tenía 18 años cuando hizo circular su soneto A ciascun'alma presa e gentil core y Guido ya andaba por la treintena. Era un rico aristócrata, acomodado, con figuración política que - creo - difícilmente habría seguido los eventuales consejos filosóficos y teológicos de un jovencito endeudado que intentaba figurar en el ámbito social y literario.

Cavalcante interrumpe el diálogo entre Dante y Farinata (If X, 52-72) y la mención del amigo Guido, obstinado en la incredulidad (averroísta o epicúrea) aclararía la razón salvífica y el significado moral del canto. Como apoyo, sigo a Antonio Lanza (de quien adopté el texto crítico desde el primer momento), porque creo que es el que -hasta prueba contraria- ha dado la interpretación más correcta y que traduzco a continuación:

¿Cómo habría podido saber que colui era Virgilio y que el cui estaba referido a Beatrice (o, peor, ¿a Virgilio mismo?)?: Todas las fuentes están concordes en presentar a Guido como un ateo; por lo tanto el cui está referido a Dios (e, para rehuír cualquier duda, lo escribo con la mayúscula). Inserto el forse entre comas para subrayar como este deba estar enlazado a per qui mi mena, no ciertamente a ebbe a disdegno: Dante, en efecto, está apenas al inicio del camino y no puede estar seguro de llegar a Dios, meta última de su viaje (Beatriz es, en efecto, el medio por el cual la razón humana, oportunamente, puede conseguir la Verdad).

Solo refiriendo el cui a Dios Cavalcante habría estado en condiciones de comprender la frase de Dante. Que, después, colui che attende là sea Virgilio poco importa; Dante no lo presenta a Cavalcante y este no podía saber quién fuese (lo

ahora Blanco Jiménez, José. "Los duo ultima: entre Tomás y Dante". Gratia non tollit naturam sed perficit eam. Sobre las relaciones y límites entre naturaleza y gracia. Actas del Segundo Congreso Internacioinal de Filosofía Tomista. Ed. Casanova, Carlos A. y Serrano Del Pozo, Ignacio. Universidad Santo Tomás. Santiago de Chile, RIL Editores, 2016, pp. 441-447. 
mismo ocurre, por ejemplo, en el episodio de Brunetto Latini). Ésta la explicación de los versos 62-63: 'aquél que espera allá a través de estos lugares tal vez me conduce a Dios, que Guido ha tenido (ebbe, usado como pretérito perfecto) en desdén" 19 .

Y agrego yo: en el $e b b e$, que Gramsci considera la palabra más importante, porque ahí cae el acento "estético" y "dramático" del verso (Gramsci, p. 78), está la clave de todo el Canto. Dante utiliza el verbo de manera ambigua a propósito. Él (como personaje) no sabe que los heréticos no conocen lo que ocurre en el presente. Pensando en ello, se demora en responder al padre de Guido y este cae abatido en la tumba. Dante personaje sabe que está vivo; Dante poeta sabe que ya está muerto. Pero ¿a dónde llegará en ese mundo de ultratumba? ¿Estará junto a su padre como epicúreo? ¿O se habrá arrepentido como lo hizo el mismísimo Manfredi, a quien colocará en el Antipurgatorio?

No me cabe duda que la Commedìa se fue reestructurando en la medida que el exul immeritus [exiliado inmerecido] la iba escribiendo. Forese Donati y Bonagiunta da Lucca estarán en el Purgatorio (entre los golosos); también Guido Guinizelli y Arnaldo Daniello (entre los lujuriosos).

A él le gustaría que Guido se salvara, pero no es el Padre Eterno. No hay que olvidar que su "poema sacro" es una obra maestra de la literatura fantástica y que como tal hay que considerarla, a pesar de que nos parezca terriblemente real.

Por ello, los que negaron la inmortalidad del alma hicieron un camino sin retorno. Tal vez para el amigo hay todavía una esperanza, pero... ¡no depende de Dante!

\section{OBRAS CITADAS}

Alessandri, Claudio (2011). Federico II di Svevia. Una vita straordinaria tra realtà e leggenda. Trento: Uni Service.

Alighieri, Dante (1968). De vulgari eloquentia Edd. Marigo, Aristide y Ricci, Pier Giorgio Ricci. Firenze: Le Monnier.

— (1995). Convivio. Ed. Brambilla Ageno, Franca. Firenze: Casa Editrice Le Lettere. (1996). La Commedìa. Testo critico secondo i più antichi manoscritti fiorentini. Nuova edizione. Ed. Lanza, Antonio. Anzio: De Rubeis. Uso las siguientes abreviaturas: If $=$ Inferno; $\mathrm{Pg}=$ Purgatorio; $\mathrm{Pd}=$ Paradiso. Todos los textos en castellano corresponden a mi traducción prosificada. Indico el número del Canto con cifra romana, los versos con cifras árabes.

Auerbach, Eric (1950). Mimesis. La representación de la realidad en la literatura occidental. México: FCE. La edición original alemana es de 1940.

${ }^{19}$ Lanza, Per qui mi mena, / forse, Cui Guido vostro ebbe a disdegno) (1996, pp. 62-63). AlPha No 49 (Diciembre 2019) PÁGS. 109-128. ISSN 07 16-4254| 125 
Barbi, Michele (1941). Con Dante e con $i$ suoi interpreti. Firenze: Le Monnier.

Benvenuto Rambaldi (1887). Comentum super Dantis Aldigherij Comoediam, nunc primum integre in lucem editum sumptibus Guilielmi Warren Vernon, curante Jacobo Philippo Lacaita, Firenze: G. Barbèra.

Blanco Jiménez, José (2016). Io dico seguitando. Studi sul testo della Commedìa e la sua data di composizione. Roma: Aracne Editrice.

(2017). "Los duo ultima: entre Tomás y Dante". Gratia non tollit naturam sed perficit eam. Sobre las relaciones y límites entre naturaleza y gracia. Actas del Segundo Congreso Internacioinal de Filosofía Tomista. Ed. Casanova, Carlos A. y Serrano Del Pozo, Ignacio. Universidad Santo Tomás. Santiago de Chile, RIL Editores, 441-447.

_ (2013). "El presunto averroísmo de Dante”. Filosofía Medieval: continuidad y rupturas, en Actas del XIV Congreso Latinoamericano de Filosofía Medieval, UNSTA (Universidad del Norte Santo Tomás de Aquino, San Miguel de Tucumán, Argentina), 11 al 14 de septiembre de 2013, edición en CD-Rom. Es consultable también en Hápax 8 (2015), 133-149.

—_ (2015). Io dico seguitando: Estudios sobre el texto de la Commedìa y su fecha de composición. Santiago de Chile: Ediciones Video Carta.

__ (2007). "Democrito che'l mondo a caso pone (If. IV, 136)", en "Bene ascolta chi la nota” (If. XV, 99) Intertextualidad clásica en la Commedia de Dante. Santiago de Chile: Ediciones Video Carta, 27-30.

—_ (2000), "Los dos Guidos y el Dolce Stil Novo". En Nunquam Florentiam Introibo" y otros ensayos sobre Dante. Santiago de Chile: Ediciones Video Carta, 77-83.

Boccaccio, Giovanni (1965). Esposizioni sopra la Comedia di Dante. Ed. Padoan, Giorgio. Tutte le opere, Milano: Mondadori.

_ (2013). Decameron. Ed. Fiorilla, Maurizio. Milano: Rizzoli.

Bozzetti, Cesare (1957). "Storia interna del canto X dell'Inferno". Studia Ghisleriana, Serie II, Vol. II, Studi Letterari per il $250^{\circ}$ aniversario della nascita di C. Goldoni. Pavia, pp. 77-127.

Cassata, Letterio (1969). "Il disdegno di Guido (Inf. X 63)". Studi danteschi XLVI, 5-49.

Corti, Maria (2003). Scritti su Cavalcanti e Dante, Torino: Einaudi.

Da Buti, Francesco (1858-62), Commento di Francesco da Buti sopra La Divina Commedia di Dante Allighieri. Ed. Giannini, Crescentino. Pisa: Fratelli Nistri.

Del Lungo, Isidoro (1926) La Divina Commedia commentata da Isidoro del Lungo. Firenze, Le Monnier.

D’Ancona, Alessandro (1912). Scritti danteschi. Firenze: Sansoni. 
D'Ovidio, Francesco (1878). "Nota sul verso X dell'Inferno: Forse cui Guido vostro ebbe a disdegno". Saggi critici. Napoli: Domenico Morano.

Fosca, Nicola (2003). Commentary, The Dartmouth Dante Project.

Frugoni, Arsenio (1966). "Il canto X dell'Inferno". Nuove letture dantesche, Casa di Dante (Roma), Firenze: Le Monnier.

Gramsci, Antonio (1996). Letteratura e vita nazionale. Roma: Editori Riuniti, $72-91$ (publicado anteriormente por Torino: Einaudi, 1950: 34-45; y en Lettere dal carcere, Torino: Einaudi, 1947: 141-144).

Della Lana, Jacopo (1915). Chiose alla Cantica dell'Inferno di Dante Alighieri scritte da Jacopo Alighieri, pubblicate per la prima volta in corretta lezione con riscontri e facsimili di codici, e precedute da una indagine critica per cura di Jarro [Piccini, Giulio]. Firenze: R. Bemporad e figlio. Consultable en www.bibliotecaitaliana.it. Landino, Cristoforo (1481). Comento di Christophoro Landini fiorentino sopra la Comedia di Danthe Alighieri poeta fiorentino. Firenze: Nicholo di Lorenzo della Magna.

Lanza, Antonio (1996). (Dante, La Commedia: comentario y notas).

Le Goff, Jacques (1984). Gli intellettuali nel Medioevo, Milano: Mondadori ( $1^{\mathrm{a}}$ edición: Les intellectuels au Moyen Age. Paris: Editions du Seuil, 1957). Existe traducción castellana: Barcelona: Editorial Gedisa, 1996.

Liber Pontificalis (1886). Ed. Duchesne, Louis. Paris: Ernest Thorin Éditeur.

Li Vigni, Benito (2011). Federico II: il principe sultano. Roma: Armando.

L'Ottimo Commento della Divina Commedia Testo inedito d'un contemporaneo di Dante citato dagli Accademici della Crusca. (1827-1829). Ed. Torri, Alessandro. Pisa: Niccolò Capurro. Ha sido atribuido a Andrea Lancia, un notario florentino, que vivió entre 1296 y 1357. Hay una reimpresión anastática a cargo de Mazzoni, Francesco. Bologna: Forni, 1995. Del Inferno hay una edición más reciente: L'ultima forma dell' "Ottimo commento». Chiose sopra la Comedia di Dante Allegieri fiorentino tracte da diversi ghiosatori. Ed. Di Fonzo, Claudia. Inferno. Ravenna: Longo. Disponible en: http://dante.dartmouth.edu/ commentaries.php.

Marti, Mario (1970). "Guido Cavalcanti”. Enciclopedia Dantesca, Roma: Istituto della Enciclopedia Italiana, I, 893a-895a.

Mazzeo, Joseph A. (1958). "Dante and Epicurus". Comparative Literature X, 106-120.

Mazzoni, Francesco (1976) "Il canto V dell' Inferno", en Lectura Dantis Romana: Letture degli anni 1973-78. Roma: Bonacci.

Nardi, Bruno (1965). "Il canto XI dell'Inferno", Nuova Lectura Dantis Ed. Chimenz, Siro Amedeo. Roma: Signorelli, 1951 (después en Letture dantesche. Ed. Getto, Giovanni. Firenze: Sansoni, 193-207). 
_ (1942). 'L'averroismo dell' primo amico di Dante". Studi Danteschi, XXV (1940): 43-79; después en Dante e la cultura medievale, Laterza, Bari 1942; 1949², 93-129; cito de la edición 1985, 81-107.

Ottokar, Nicolai Petrovič (1948) Studi comunali e fiorentini, La Nuova Italia, Firenze,115-123.

Padoan, Giorgio (1959). "Il canto degli Epicurei”, en Convivium, n.s. I, 12-39.

Pagliaro, Antonino (1953). "Il disdegno di Guido". Saggi di critica semantica. MessinaFirenze: D’Anna, 1953, 357-380. Cfr. también Ulisse. Ricerche semantiche sulla Divina Commedia, Messina-Firenze: D’Anna, 1967, I, 185-224.

Pagnoni-Spurlese, Maria Rita (1974). "Prime note sulla tradizione medioevale e umanistica di Epicuro". Annali Scuola Normale Pisa, s. 3, XXIV, 1443-1477.

Pasquini, Emilio (2012). "Dante e Farinata: da Empoli a Giosafat". Tra storia e letteratura: il Parlamento di Empoli di 1260. Ed. Arrighi, Vanna. Firenze: Leo S. Olschki.

Rastelli, Dario (1948). Restauri danteschi: Proposte per una rilettura del canto di Farinata. Pavia: La Tipografica Ticinese.

Trucchi, Ernesto (1936). Esposizione della Divina Commedia. Milano: L. Toffaloni.

Vasoli, Cesare (1970). "Averroè”. Enciclopedia Dantesca. Roma: Istituto della Enciclopedia Italiana, I 473b-479b; “Averroismo". Ibidem: I, 479b-481a.

Velardi, Francesco (2007). "I due Guidi. Cavalcanti e la data di morte nel necrologio di Santa Reparata". Studi Danteschi, LXXII, 239-263.

Villani, Giovanni (s/f). Nuova Cronica. Disponible en www.liberliber.it. 